\title{
Vicious-circle behavior involves new learning
}

\author{
SANFORD J. DEAN \\ Northern Illinois University, DeKalb, Illinois \\ M. RAY DENNY \\ Michigan State University, East Lansing, Michigan \\ and \\ THOMAS BLAKEMORE \\ Northern Illinois University, DeKalb, Illinois
}

\begin{abstract}
Following escape training in a straight runway, hooded rats were given differential treatment during extinction: Midsegment punishment on every trial, midsegment punishment on the first four trials only, midsegment punishment on the first trial only, startbox punishment on the first four trials only, or no punishment. Punishment led to vicious-circle behavior, that is, greater resistance to extinction than in a no-punishment condition, only when it was administered in the midsegment of the runway on four or more trials. The results support the interpretation that, during extinction, running is learned to the altered stimulus conditions present in the start area.
\end{abstract}

Vicious-circle (VC), or self-punitive, behavior refers to persistent responding that results in punishment. In the typical demonstration of the phenomenon (e.g., Brown, Martin, \& Morrow, 1964), animals are trained to escape from shock by traversing a runway and entering a shockfree goalbox. During extinction, one group of subjects receives no shock, whereas a punished group encounters shock, but only in a midportion of the runway. Punished extinction (PE) subjects continue to cross the shock segment and enter the goalbox for many trials, whereas regular extinction (RE) subjects run slower and stop running sooner. The greater resistance to extinction shown by the PE subjects than by the RE subjects is the measure of VC behavior.

According to the Mowrer-Brown conditioned fear hypothesis (Brown, 1969), PE subjects continue to run and receive shock because the running response learned during training is reinforced by pain and fear reduction when the subject crosses the shock segment and escapes to the goalbox. In addition, the shock provides further fear conditioning, with fear generalizing to the start area in sufficient magnitude to maintain VC behavior.

A frequent observation in VC experiments is that subjects slow up on the first few extinction trials, particularly in the preshock area, but punished subjects then show improved performance over trials, sometimes attaining running speeds that exceed those achieved during escape training. This improvement in performance over trials has

This research was conducted while $M$. Ray Denny was a visiting professor at Northern Illinois University. Thomas Blakemore is now at the University of Wisconsin-Stout, Menomonie, WI. Requests for reprints should be sent to Sanford J. Dean, Department of Psychology, Northern Illinois University, DeKalb, IL 60115. been interpreted as new learning during extinction (Beecroft \& Bouska, 1967; Brown, 1969). An initial decrement in performance is not surprising. The absence of shock in the startbox and preshock area eliminates the motivational component due to pain and modifies the stimuli that have become associated with running during escape training. The first few extinction trials are probably critical in establishing VC behavior. Forward locomotion is elicited by fear of the cues in the start area, and the animal continues down the alley, despite midsegment punishment, because running has been conditioned to shock and shock-produced stimuli during escape training (Brown, 1969; Brown \& Cunningham, 1981). Incompatible withdrawal responses elicited by shock in the intermediate segment may, however, on occasion compete successfully with the running response and lead to early extinction. Yet most PE subjects make the transition, learn to run under the modified stimulus conditions, and get locked into the vicious circle.

In an earlier study, Rands and Dean (1977) employed a Y maze to investigate the effects of the availability of an alternative running response on response persistence during extinction. In a choice condition, during extinction, rats given equal amounts of escape training in each arm of the Y maze had access to both a shock-free arm and an arm containing midsegment shock. In a PE condition, both arms contained midsegment shock, and in an RE condition, both arms were shock free. The usual VC effect occurred. In trials to extinction, the choice group was intermediate between the PE and RE groups but was not significantly different from either. An inspection of the data indicated that no subject in the choice condition received more than eight shocks during extinction and that all subjects had switched their choices completely to the 
safe arm by the 15 th trial. Some subjects extinguished promptly, like RE subjects, whereas others were comparable to PE subjects. A breakdown of the number of shocks received indicated that subjects that received no more than two shocks extinguished in a mean of 5.4 trials, whereas those that received three to eight shocks extinguished in a mean of 41.2 trials. A possible interpretation of this finding is that three or more midsegment shocks promoted learning to run under the modified stimulus conditions present during extinction (i.e., no shock in the start area). Another possibility is that three or more midsegment shocks maintained the fear of the startbox through stimulus generalization. Either possibility would have resulted in greater resistance to extinction. The present study was designed to test these hypotheses.

\section{METHOD}

\section{Subjects and Design}

The subjects were 65 male hooded rats, between 90 and 110 days of age, bred in the colony maintained by the Psychology Department of Northern Illinois University. All subjects were housed individually during the experiment and were allowed continuous access to food and water in the home cage. Thirteen subjects were assigned to each of the following groups, which differed only in terms of treatment during extinction: (1) a group that received $100 \%$ midsegment shock during extinction (Group PE-100\%), (2) a group that received midsegment shock only on the first four trials (Group PE-4), (3) a group that received midsegment shock on only the first trial (Group PE-1), (4) a group that received no shock (Group $\mathrm{RE}$ ), and (5) a group that received shock in the startbox on the first four trials (Group SB-4). The latter group controlled for any additional fear through generalization from four midsegment shocks and provided a critical comparison for testing the hypothesis that the PE group learned a new habit during the early stages of extinction.

\begin{abstract}
Apparatus
The apparatus, similar to the straight alley apparatus described by Brown et al. (1964), consisted of a white, grid-floored startbox, a white, grid-floored runway, and a black goalbox with a solid floor covered with cageboard. The startbox was two tiered and had a trap-door floor that, when released, dropped the subject onto the grid floor of the lower compartment. The runway was $183 \mathrm{~cm}$ long and was divided into three 61-cm segments, wired separately. A constant-current ac shock of .5 mA (nominal) provided by a Lehigh Valley shocker could be delivered to the lower tier of the startbox and to any or all runway segments.
\end{abstract}

\section{Procedure}

On Days 1 and 2, the subjects received 5 min of handling. On Day 3, following $5 \mathrm{~min}$ of handling, the subjects received $5 \mathrm{~min}$ of exploration of the apparatus, with all doors open and the shock off prior to the start of training. Two shaping trials, 13 escape training trials, and the extinction trials were completed in a single session. The goalbox was connected directly to the startbox for the first trial. One segment was inserted between the goalbox and the startbox for the second trial. Following the second trial, the remaining two segments were inserted for the 13 escape training trials and the extinction trials. Shock was administered in the lower portion of the startbox and throughout the runway on all shaping and training trials. The intertrial interval (ITI) was $1 \mathrm{~min}$, measured from entry into the goalbox to release of the trap door for the next trial. During the ITI, the subjects were confined to the goalbox for the first $30 \mathrm{sec}$ and then were carried in a holding cage to the startbox to begin the next trial.

Extinction trials were begun immediately following the last escape trial and, except for the shock condition, were identical in procedure to escape-training trials. All subjects were run to an extinction criterion of 160 -sec trial or 100 trials.

\section{RESULTS AND DISCUSSION}

The initial comparability of the groups was evaluated with a one-way ANOVA of the speed of running on the last two escape training trials in acquisition. The results indicated that the groups did not differ significantly $[F(4,60)=1.30, p>.20]$. Thus, any difference found in extinction cannot be attributed to initial differences between the groups.

The mean number of trials to the extinction criterion was as follows: Group PE-100\%, 98.8; Group PE-4, 63.5; Group PE-1, 41.3; Group RE, 36.7; and Group SB-4, 38.4. A one-way ANOVA indicated that the groups differed significantly $[\mathrm{F}(4,60)=25.23, \mathrm{p}<$ .001]. Newman-Keuls comparisons indicated that Groups PE-100\% and PE-4 were both significantly more resistant to extinction $(\mathrm{ps}<.01)$ than each of the other three groups, which did not differ among themselves. Group PE- $100 \%$ was also significantly more resistant to extinction than Group PE-4 ( $p<.001)$.

Midsegment shock on the first four extinction trials clearly promoted running in Group PE-4 in the absence of further shock. Midsegment shock on only the first trial or shock in the startbox on the first four trials did not affect response persistence. These findings are consistent with the hypothesis that, during early PE trials, rats learn to run in the altered stimulus context of no shock in the preshock area and that the location of the shock is a critical factor in this learning. In other words, midsegment shock does not simply retard extinction through generalization of fear back to the start area; it also mediates the initial transfer of the running response to the new stimulus context and subsequently strengthens that response by providing the conditions for additional learning.

Perconte, Benson, and Butler (1981) suggested that, during PE, fear continues to be conditioned to the alley segment immediately preceding shock. Perconte et al. offered an account of their stimulus change data based on the Mowrer-Brown (Brown, 1969; Melvin, 1971) conditioned-fear hypothesis, which is equally applicable to the current findings. It is assumed that, during escape training, fear is conditioned to the alley stimuli and that forward locomotion is conditioned to the external stimuli as well as to the stimuli produced by fear. At the beginning of extinction, the absence of shock in the preshock area results in a stimulus generalization decrement in fear and a weaker running response. However, the amount of fear still present in the preshock area is sufficient to motivate the subject to run forward to the midsegment, where shock elicits further forward locomotion, carrying the subject down the runway to the goalbox, where running is reinforced by pain and fear reduction. On subsequent trials, fear is conditioned rapidly to the modified cues in the preshock area because of the optimal location of this area relative to the shock. Subsequent trials also lead to the strengthening of the running response by fear and pain reduction. In summary, midsegment shock during extinc- 
tion serves several functions in the development of the new learning necessary for VC behavior to occur. First, midsegment shock elicits forward locomotion; second, it serves as the unconditioned stimulus for the conditioning of fear to the modified stimuli in the preshock area; and finally, it leads to the reinforcement of the running response through pain reduction.

\section{REFERENCES}

BEECroft, R. S., \& BouSKA, S. A. (1967). Learning self-punitive running. Psychonomic Science, 8, 107-108.

Brown, I. S. (1969). Factors affecting self-punitive behavior. In B. A. Campbell \& R. M. Church (Eds.), Punishment and aversive behavior (pp. 467-514). New York: Appleton-Century-Crofts.
Brown, J. S., \& Cunningham, C. L. (1981). The paradox of persisting self-punitive behavior. Neuroscience and Behavioral Reviews, $\mathbf{5}$, 343-354.

Brown, J. S., Martin, R. C., \& Morrow, M. W. (1964). Self-punitive behavior in the rat: Facilitative effects of punishment on resistance to extinction. Journal of Comparative and Physiological Psychology, 57, 127-133.

Melvin, K. B. (1971). Vicious circle behavior. In H. D. Kimmel (Ed.), Experimental psychopathology: Recent research and theory. New York: Academic Press.

Perconte, S. T., Benson, B. A., \& Butler, D. L. (1981). Effects of stimulus change in prepunishment alley segments on self-punitive behavior. Animal Learning \& Behavior, 9, 21-27.

Rands, B. A., \& DEAN, S. J. (1977). Vicious-circle behavior in the $\mathrm{Y}$ maze. Learning and Motivation, 8, 62-68.

(Manuscript received for publication December 17, 1984.) 